\title{
FEASIBILITY OF ETHANOL PRODUCTION USING THE WHOLE SUGARCANE BIOMASS
}

\author{
SANDRA CERQUEIRA PEREIRA ${ }^{1}$, LARISSA MAEHARA ${ }^{1,2}$, CRISTINA MARIA \\ MONTEIRO MACHADO ${ }^{3}$ AND CRISTIANE SANCHEZ FARINAS ${ }^{1,2}$ \\ ${ }^{1}$ Brazilian Agricultural Research Corporation, Embrapa Instrumentation \\ ${ }^{2}$ Federal University of São Carlos, Chemical Engineering Department \\ ${ }^{3}$ Brazilian Agricultural Research Corporation, Embrapa Agroenergy \\ E-mail: sandracerqueirapereira@gmail.com
}

\begin{abstract}
Each ton of processed sugarcane generates about $280 \mathrm{~kg}$ of residues (bagasse, straw and tops). The full use of sugarcane biomass could greatly improve the ethanol productivity without expanding the cultivated areas. Bagasse has been widely studied for ethanol production unlike other sugarcane parts. Hence, we assessed the use of the whole sugarcane biomass (bagasse, straw and tops) for ethanol production. Biomasses were pretreated with $1.5 \%$ (w/v) sulfuric acid at $10 \%$ solids and then they were hydrolyzed by commercial enzymes at $30 \mathrm{FPU} / \mathrm{g}_{\text {glucan }}$. Hydrolysates were fermented by industrial strain of Saccharomyces cerevisiae. Tops were the most susceptible to enzymatic degradation reaching glucose levels up to $40 \mathrm{~g} / \mathrm{L}$ while the highest efficiency of fermentation (up to 74\%) was found for straw. Bagasse achieved lower results than the other parts. Thus, the potential application of sugarcane biomass for ethanol production can be clearly improved with the combined use of bagasse, straw and tops.
\end{abstract}

\section{INTRODUCTION}

The growing concern over the shortage of oil reserves allied to the need for environmental preservation are the main drivers of the search for viable alternatives to the production of sustainable fuels. In this context, Brazil occupies a prominent position and is moving forward to the replacement of fossil fuels by renewable bioethanol made from sugarcane. In the 2012/13 season, about 600 million tons of sugarcane was processed by the Brazilian mills, generating approximately 280 million tons of residues. This sugarcane biomass is mainly formed by two carbohydrates (cellulose and hemicellulose) embedded in a lignin matrix, making it a highly recalcitrant material.

After sugarcane harvest is generated the trash, which is composed of green and dried leaves, forming the straw, and the tops, which is the piece of sugarcane plant between the top end and the last stalk node. Then, the milling of the sugarcane to extract the juice generates the bagasse. Moreover, trash and bagasse have been typically burned (Canilha et al., 2012). However, this reality is changing due to the damage caused to the environment which led to stricter laws in order to gradually reduce the burning for the next years (Leal et al., 2013). In this prospecting, the availability of these lignocellulosic residues will rise which is essential for the viability of cellulosic ethanol production process (Macrelli et al., 2014). 
Several studies have been undertaken for ethanol production using sugarcane bagasse. Nevertheless, there are rather few reports on the assessment of the other parts of sugarcane biomass (straw and tops). The proper use of this whole lignocellulosic biomass can potentially result in significant increases in the production of ethanol per hectare without the need of extending the cultivated area or competing with the production of sugar or any other food. With this motivation, the present study aimed to evaluate the residues (bagasse, straw and tops) from four varieties of sugarcane (SP791011, RB867515, SP813250 and RB92579) for the production of ethanol using a model process selected by Brazilian Agricultural Research Corporation (Embrapa).

\section{MATERIALS AND METHODS}

\subsection{Materials}

Three untreated residues (bagasse, straw and tops) from the processing of four varieties (SP791011, RB867515, SP813250 and RB92579) of sugarcane (Sumauma Mill, Brazil) were used in this study. A commercial enzymatic extract, Cellic ${ }^{\circledR} \mathrm{CTec} 2$ (Novozymes, Brazil) was used for enzymatic hydrolysis of the biomasses. An industrial strain of Saccharomyces cerevisiae, CAT-1 (Jalles Machado Mill, Brazil) was used for alcoholic fermentation.

\subsection{Methods}

Preparation of biomass: The three untreated residue parts (bagasse, straw and tops) from the processing of four varieties of sugarcane (SP791011, RB867515, SP813250 and RB92579) were dried at $45{ }^{\circ} \mathrm{C}$ and processed in a knife mill with granulometry not exceeding $2 \mathrm{~mm}$. Next, biomasses were pretreated using $1.5 \%$ (w/v) sulfuric acid at a solids loading of $10 \%$ at $121{ }^{\circ} \mathrm{C}$ for 30 minutes.

Chemical characterization: Chemical composition of the biomasses was determined according to Gouveia et al. (2009) in terms of the contents of cellulose, hemicellulose and lignin.

Enzymatic hydrolysis: Pretreated materials were submitted to enzymatic hydrolysis in $0.1 \mathrm{M}$ citrate buffer $\mathrm{pH} 5.0$ at a solid/liquid ratio of 1/10 using an enzyme loading of 30 FPU per gram of cellulose residual in the pretreated material. Enzymatic activity was previously determined according to Ghose (1987). Assays were done in shaker at $50{ }^{\circ} \mathrm{C}$ and $200 \mathrm{rpm}$ for $24 \mathrm{~h}$. Glucose production over time was monitored by an enzymatic kit (Doles, Brazil).

Alcoholic fermentation: The hydrolysates obtained after the enzymatic hydrolysis step were fermented by industrial strain of $S$. cerevisae. But before that, glucose was added up to the concentration of $100 \mathrm{~g} / \mathrm{L}$. The medium was inoculated with $25 \mathrm{~g} / \mathrm{L}$ of yeast. Experiments were conducted in shaker at $31{ }^{\circ} \mathrm{C}$ and $100 \mathrm{rpm}$ for $8 \mathrm{~h}$. As routine analysis, glucose monitoring over time was done by an enzymatic kit and ethanol was monitored by high performance liquid chromatography according to Gouveia et al., 2009. The ethanol yield coefficient was calculated using Equation 1.

$$
Y_{P / S}=\frac{\left(P-P_{0}\right)}{\left(S_{0}-S\right)}
$$


Statistical analysis: Tukey Test with a significance level of 0.05 .

\section{RESULTS AND DISCUSSION}

Table 1 presents the contents of cellulose, hemicellulose and lignin for the three untreated residue parts (bagasse, straw and tops) from the processing of four varieties of sugarcane. It is observed that for all sugarcane varieties, the tops have a lower lignin and higher hemicellulose content while the straw has a higher level of cellulose. The evaluation of the chemical composition is of extreme importance because the vegetal biomass conversion into biofuels (steps of pretreatment, enzymatic hydrolysis and fermentation) is clearly dependent of chemical and morphological features inherent to these lignocellulosic materials.

Table 1 - Contents of cellulose, hemicellulose and lignin for bagasse, straw and tops from the processing of four varieties of sugarcane $(\%)$

\begin{tabular}{cccccc}
\hline Varieties & Symbol & Residues & Hemicellulose & Lignin & Celullose \\
\hline \multirow{2}{*}{ SP791011 } & & Straw & 35.07 & 11.13 & 41.09 \\
& & Tops & 35.72 & 8.00 & 35.60 \\
& & Bagasse & 28.45 & 13.81 & 34.68 \\
\hline \multirow{2}{*}{ RB867515 } & M & Straw & 35.93 & 12.04 & 42.12 \\
& & Tops & 37.27 & 8.95 & 35.02 \\
& & Bagasse & 28.86 & 13.45 & 38.47 \\
\hline \multirow{2}{*}{ SP813250 } & & Straw & 36.53 & 11.33 & 41.27 \\
& & Tops & 38.79 & 9.08 & 34.05 \\
& & Bagasse & 29.19 & 11.83 & 36.13 \\
\hline \multirow{2}{*}{ RB92579 } & & Straw & 37.07 & 11.26 & 39.91 \\
& & Tops & 38.76 & 5.59 & 37.08 \\
& & Bagasse & 31.02 & 10.89 & 39.07 \\
\hline
\end{tabular}

Here, we evaluated the use of bagasse, straw and tops from different varieties of sugarcane in order to contribute to bioethanol production process developments using the whole sugarcane biomass through the prior analysis of the individual contributions of each part of the sugarcane. Figure 1 shows the enzymatic hydrolysis of the pretreated residue parts from the four varieties of sugarcane. Furthermore, Table 2 presents the conversion of cellulose to glucose. In the Figure 1, it is possible to notice that regardless of the variety of sugarcane, the tops are highlighted as the material more susceptible to enzymatic degradation. This observation is confirmed by the conversion, as can be seen in Table 2. 

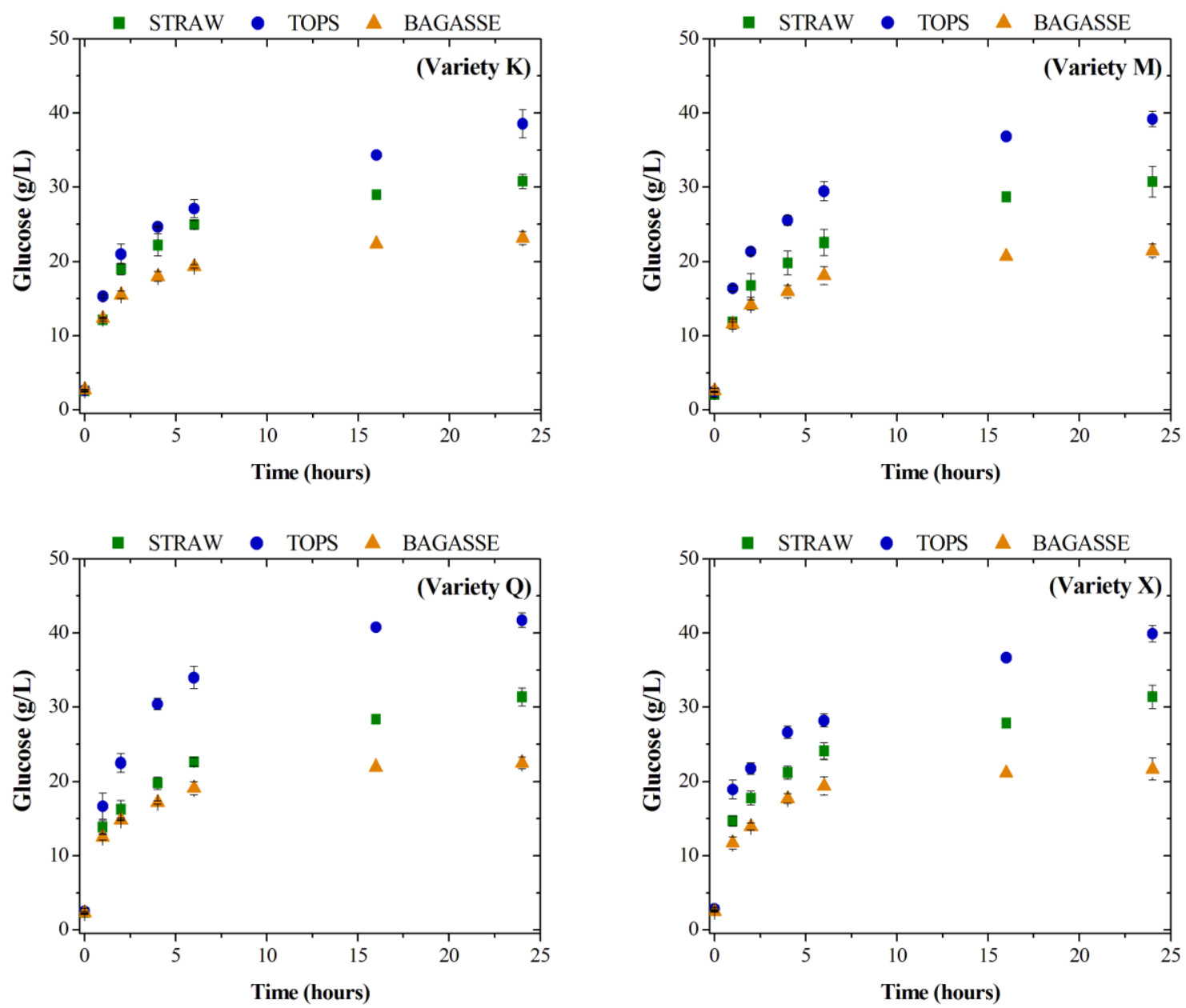

Figure 1 - Profiles of glucose production during enzymatic hydrolysis of the pretreated residue parts from the four varieties of sugarcane.

Table 2 - Cellulose conversion after 24 hours of enzymatic hydrolysis of bagasse, straw and tops from the processing of four varieties of sugarcane $(\%)$

\begin{tabular}{ccccc}
\hline Varieties & Symbol & Straw & Tops & Bagasse \\
\hline SP791011 & K & 52,53 & 65,54 & 35,82 \\
\hline RB867515 & M & 51,68 & 67,45 & 35,45 \\
\hline SP813250 & Q & 51,26 & 72,73 & 38,50 \\
\hline RB92579 & $\mathrm{X}$ & 51,76 & 64,37 & 33,09 \\
\hline
\end{tabular}


Figure 2 shows the fermentation of the hydrolysates obtained from the different varieties of sugarcane. In terms of the fermentation, regardless of the sugarcane variety, hydrolysates obtained from the straw are highlighted in relation to the other residue parts, as can be seen in Figure 2. The observation of the consumption of glucose for the different residues of the same variety of sugarcane during the fermentation clearly shows that the presence of inhibitory substances may be differentially interfering in the metabolism of the yeast since the acid pretreatment that was used in this study is known by the production of acetic acid, furfural and hydroxymethylfurfural (Moutta et al., 2013). Thus, it can be suggested that each part of the sugarcane responds differently to the conditions of pretreatment, enzymatic hydrolysis and fermentation, and this response must be closely linked to the physical properties and chemical composition of these residues (Menon\& Rao, 2012). It is noteworthy that the results for the sugarcane bagasse were lower in both process steps (see Figures 1 and 2).
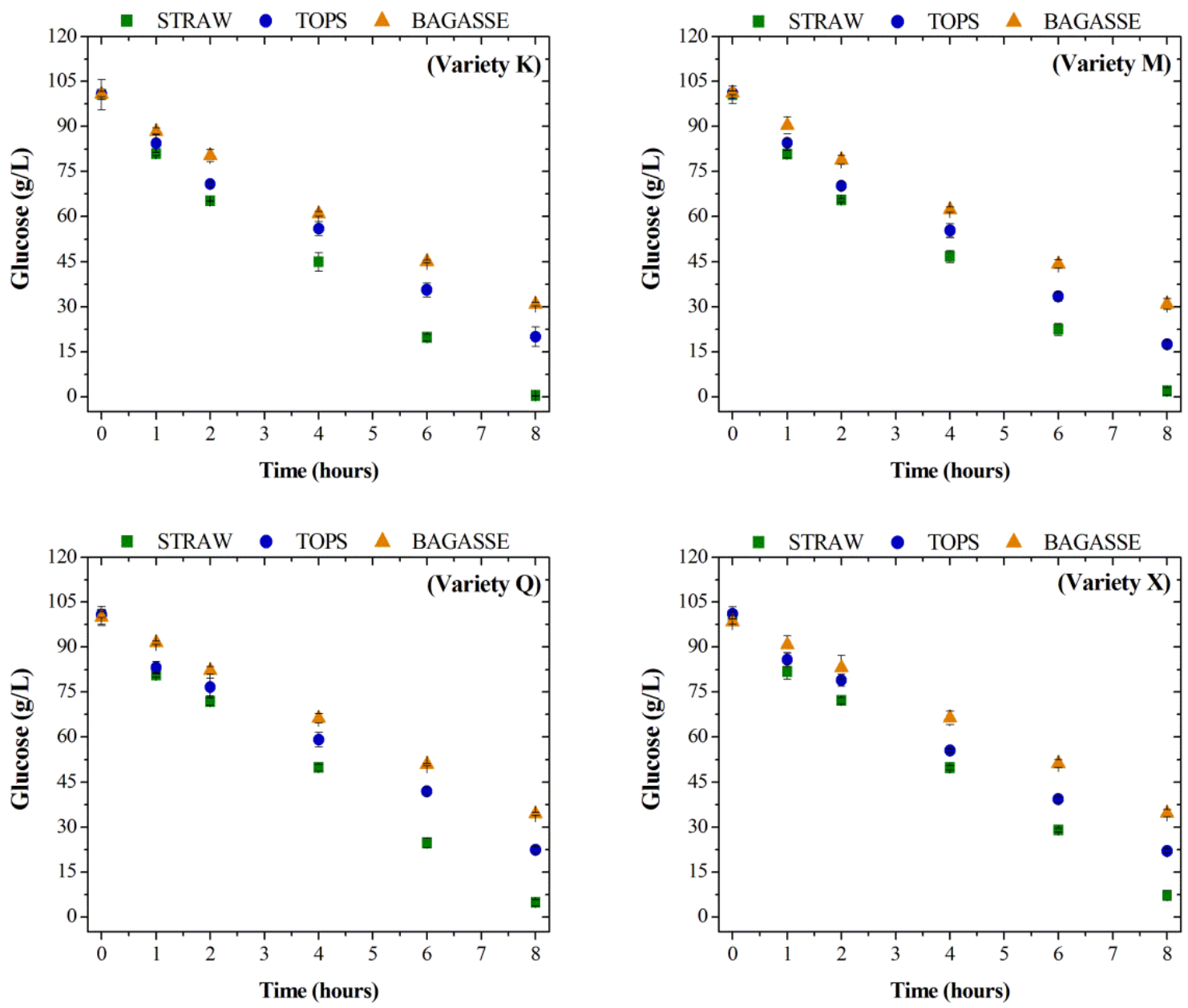

Figure 2 - Profiles of glucose consumption during fermentation of the hydrolysates obtained from the processing of the different varieties.

Santos et al. (2013) employed the hydrothermally pretreated trash for the bioethanol production. According to the authors, the step of enzymatic saccharification was significantly improved with the use of this pretreatment technology. The best condition tested resulted in 
approximately $43 \mathrm{~g} / \mathrm{L}$ of glucose. It is worth noting that the aforementioned study employed the trash, that is, straw and tops together. Here we have employed straw and tops separately, reaching $40 \mathrm{~g} / \mathrm{L}$ of glucose release from the experiments with the tops as a starting biomass and $29 \mathrm{~g} / \mathrm{L}$ for the straw. This observation suggests that the use of the tops appears to contribute to the high conversion of cellulose to glucose found by Santos et al. (2013), which is also probably related to the lower levels of lignin in the composition of the tops (see Table 1).

Another important point indicates that the variety of sugarcane does not seem to be a factor of great influence for cellulosic ethanol production process. Thus, for this purpose, agronomic characteristics would have to be taken into account in order to choose the cultivation of a particular variety in the field, for example, adaptation of the specific needs of each variety to the regional conditions aiming to promote higher yields at the lowest possible cost. This finding is an important indication of the possibility of cultivating different varieties of sugarcane without affecting the final production of cellulosic ethanol in the Brazilian mills.

The fermentation efficiency was calculated as a percentage regarding the theoretical value ( $\mathrm{Y}_{\mathrm{P} / \mathrm{S}}$ equal to 0.511 ). The results are shown in Table 3. This parameter was chosen in this study because it provides more comprehensive information for ethanol production process in terms of the amount of glucose which was required to produce a given amount of ethanol. In the fermentation process, comparing the data of fermentation efficiency of the different varieties for the same material, the results showed that there was no significant difference between the varieties of straw, bagasse or tops after 8 hours of fermentation of the respective hydrolysates (Tukey Test with a significance level of 0.05 ).

Table 3 - Fermentation efficiency of the hydrolysates from enzymatic hydrolysis of bagasse, straw and tops from the processing of four varieties of sugarcane $(\%)$

\begin{tabular}{ccccc}
\hline Varieties & Symbol & Straw & Tops & Bagasse \\
\hline SP791011 & K & 74,70 & 65,52 & 54,69 \\
\hline RB867515 & M & 74,19 & 64,47 & 55,91 \\
\hline SP813250 & Q & 73,90 & 63,85 & 58,16 \\
\hline RB92579 & $\mathrm{X}$ & 73,74 & 63,53 & 56,30 \\
\hline
\end{tabular}

As mentioned before, the statistical analysis confirms that the variety of sugarcane didn't show decisive influence on the overall production process of ethanol. On the other hand, is essential to know that it is feasible to use the surplus of straw and tops for the production of cellulosic ethanol, since in the enzymatic hydrolysis and fermentation, these parts of the sugarcane showed better results than the bagasse, which is already being widely used and studied as a feedstock for production of second generation ethanol. In this sense, a promising alternative would 
be to use a mixture of bagasse, straw and tops, so that it would possible to achieve an increase in final ethanol production, compared with processes that would use only bagasse as lignocellulosic biomass.

\section{CONCLUSION}

Three residues (straw, bagasse and tops) from the four varieties of sugarcane (SP791011, RB867515, SP813250 and RB92579) were evaluated for the production of second generation ethanol using a process selected by Embrapa aiming to analyze the feasibility of using the whole sugarcane biomass. The results have shown that there was no significant difference among the different varieties of sugarcane for the same residue, but instead there was a significant difference for the different residues of the same variety of sugarcane. The best results were achieved in the enzymatic hydrolysis of the tops (up to $40 \mathrm{~g} / \mathrm{L}$ ) and in the alcoholic fermentation of the hydrolysates from straw (up to 74\% efficiency). Therefore, the potential application of bagasse which is already being studied can be further extended with the combined use of tops and straw from sugarcane.

\section{REFERENCES}

CANILHA, L.; CHANDEL, A. K.; MILESSI, T. S. S.; ANTUNES, F. A. F.; FREITAS, W. L. C.; FELIPE, M. G. A.; SILVA, S. S. Bioconversion of Sugarcane Biomass into Ethanol: An Overview about Composition, Pretreatment Methods, Detoxification of Hydrolysates, Enzymatic Saccharification, and Ethanol Fermentation. J Biomed Biotechnol, v. 2012, p. 1$15,2012$.

GHOSE, T. K. Measurement of cellulase activities. Pure Appl Chem, v. 59, p. 257-268, 1987.

GOUVEIA, E. R.; NASCIMENTO, R. T.; SOUTO-MAIOR, A. M. Validação de metodologia para a caracterização química de bagaço de cana-de-açúcar. Quim Nova, v. 32, p. 15001503, 2009.

LEAL, M. R. L. V.; GALDOS, M. V.; SCARPARE, F. V.; SEABRA, J. E. A.; WALTER, A.; OLIVEIRA, C. O. F. Sugarcane straw availability, quality, recovery and energy use: A literature review. Biomass Bioenerg, v. 53, p. 11-19, 2013.

MACRELLI, S.; GALBE, M.; WALLBERG, O.Effects of production and market factors onethanol profitability for an integrated first andsecond generation ethanol plant using the wholesugarcane as feedstock. Biotechnol Biofuels, v. 7, p. 26-42, 2014.

MENON, V.; RAO, M. Trends in bioconversion of lignocellulose: Biofuels, platform chemicals \& biorefinery concept. Prog Energ Combust, v. 38, p. 522-550, 2012.

MOUTTA, R. O.; SILVA, M. C.; CORRALES, R. C. N. R.; CERULLO, M. A. S.; FERREIRALEITÃO, V. S.; BON, E. P. S. Comparative Response and Structural Characterization of Sugarcane Bagasse, Straw and Bagasse-Straw 1:1 Mixtures Subjected to Hydrothermal Pretreatment and Enzymatic Conversion. J Microbial Biochem Technol, v. 5, p. 1-12, 2013.

SANTOS, F. A.; QUEIROZ, J. H.; COLODETTE, J. L; MANFREDI, M.; QUEIROZ, M. E. L. R.; CALDAS, C. S.; SOARES, F. E. F. Otimização do pré-tratamento hidrotérmico da palha de cana-de-açúcar visando à produção de etanol celulósico. Quim Nova, v. 15, p. 1-7, 2013. 


\section{ACKNOWLEDGEMENTS}

The authors would like to thank Brazilian research-funding agencies (CAPES, CNPq and FAPESP) and Embrapa. 